\title{
SocArXiv
}

Preprint : November 18, 2016

osf.io/view/socarxiv/

\section{D Scan Data for Selected Clovis-Age Artifacts from the Gault Site (41BL323), Central Texas, USA}

\author{
Robert Z. Selden Jr. \\ Stephen F. Austin State University \\ Nancy Velchoff \\ Texas State University
}

\author{
Thomas J. Williams \\ Texas State University \\ Michael B. Collins \\ Texas State University
}

\begin{abstract}
On August 19, 2016, selected Clovis artifacts from the Gault site (41BL323) were scanned in advance of a large collaborative research project. These data were collected using a NextEngineHD running ScanStudioHD Pro, and were post-processed in Geomagic Design X 2016.0.1. All data associated with this project have been made publicly available (open access) and are accessible in Zenodo under a Creative Commons Attribution license, where they can be downloaded for use in additional projects and learning activities. These data have the capacity to augment a variety of research designs spanning the digital humanities, applications of geometric morphometrics, and many others. Additionally, these scans will augment a wide range of comparative research topics throughout the Americas and beyond. Reuse potential for these data is significant.
\end{abstract}

Keywords: Clovis, Projectile Points, 3D.

\section{Overview}

The Gault Site (41BL323), located in Central Texas, USA (Figure 1), is a large, open-air site with an extensive, stratified sequence encompassing a near-complete regional prehistoric sequence. Dense deposits of Clovis-age stone tools, manufacturing debris, and associated faunal material (e.g., mammoth, horse, and bison) have been systematically excavated from the siteCollins (2002). Overall, the Gault Clovis assemblage is comprised of approximately 600,000 artifacts, around ninety-five percent being lithic material; most recovered from nine major excavation blocks from less then three percent of the entire site. Recently published studies of the Gault Clovis materials include an analysis of incised stones Lemke et al. (2015), Clovis blade technology Williams (2016), Clovis Flake analysis Velchoff Littlefield (2015), 
and Optically Stimulated Luminescence ages of the Clovis component in Area 15 Rodrigues et al. (2016). Current analytical investigations include microscopic use-wear, geomorphological, paleomagnetic, microfossil, and starch grain analyses. Other investigations include the identification of family and/or species from fragmented faunal remains using ZooMS (Zooarchaeology by Mass Spectrometry) Keenan Early (2016); Buckley et al. (2008).

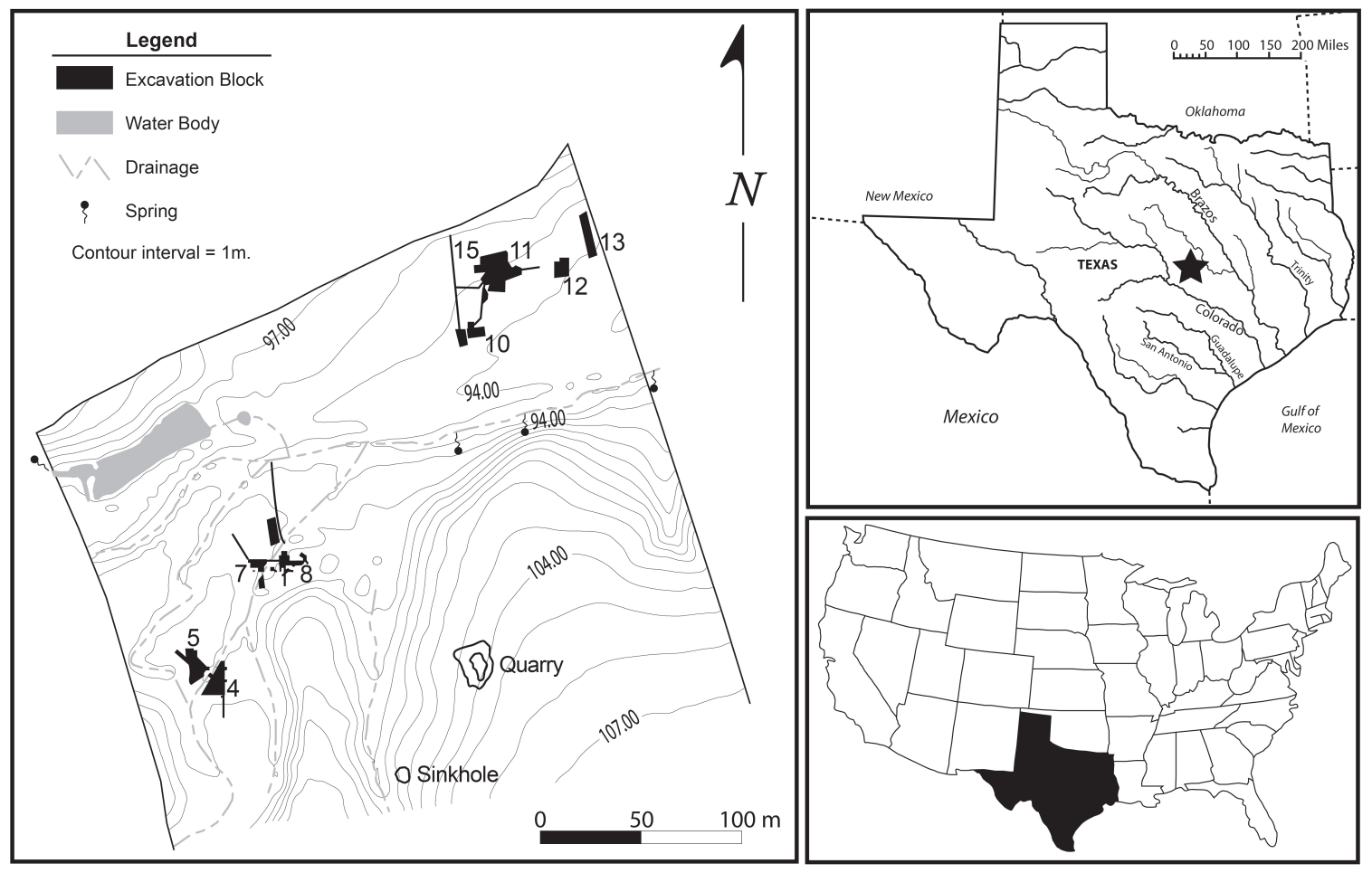

Figure 1: Map of the Gault site indicating those areas where Clovis-age deposits were discovered. The 3D scanned Clovis points were recovered from areas 4, 7, and 8 .

Lithic analysis remains ongoing and the addition of other analytical approaches, in this case, that employ 3D meshes helps to advance discussions of shape variation that occurs among these artifacts; many of which are regularly used in studies of shape using 2D data Buchanan and Collard (2010); Buchanan et al. (2011, 2007, 2012, 2013). There are many components of shape that are difficult-if not impossible-to characterize using traditional orthogonal approaches Shott and Trail (2012); Shott (2011), and are more accurately captured and analyzed in their native 3D format Shott $(2014,2015)$. These attributes can be couched in a variety of theoretical frameworks Hosfield (2009); Costin (2001, 2005); however, evolutionary archaeology remains de rigueur for geometric morphometric studies of lithic artifacts Lycett (2015). While the production of 3D data are labor and time-intensive (although see Ahmed et al. (2014)), the benefits can be seen in their contribution to conservation Kuzminsky and Gardiner (2012), participatory digital archaeology Morgan and Eve (2012), and dynamic illustrations Magnani (2014); Carlson (2014). Furthermore, with the ability to convert these $3 \mathrm{D}$ scans (Figure 2) into printed replicas, new avenues in public outreach and education can be explored Means et al. (2013). 


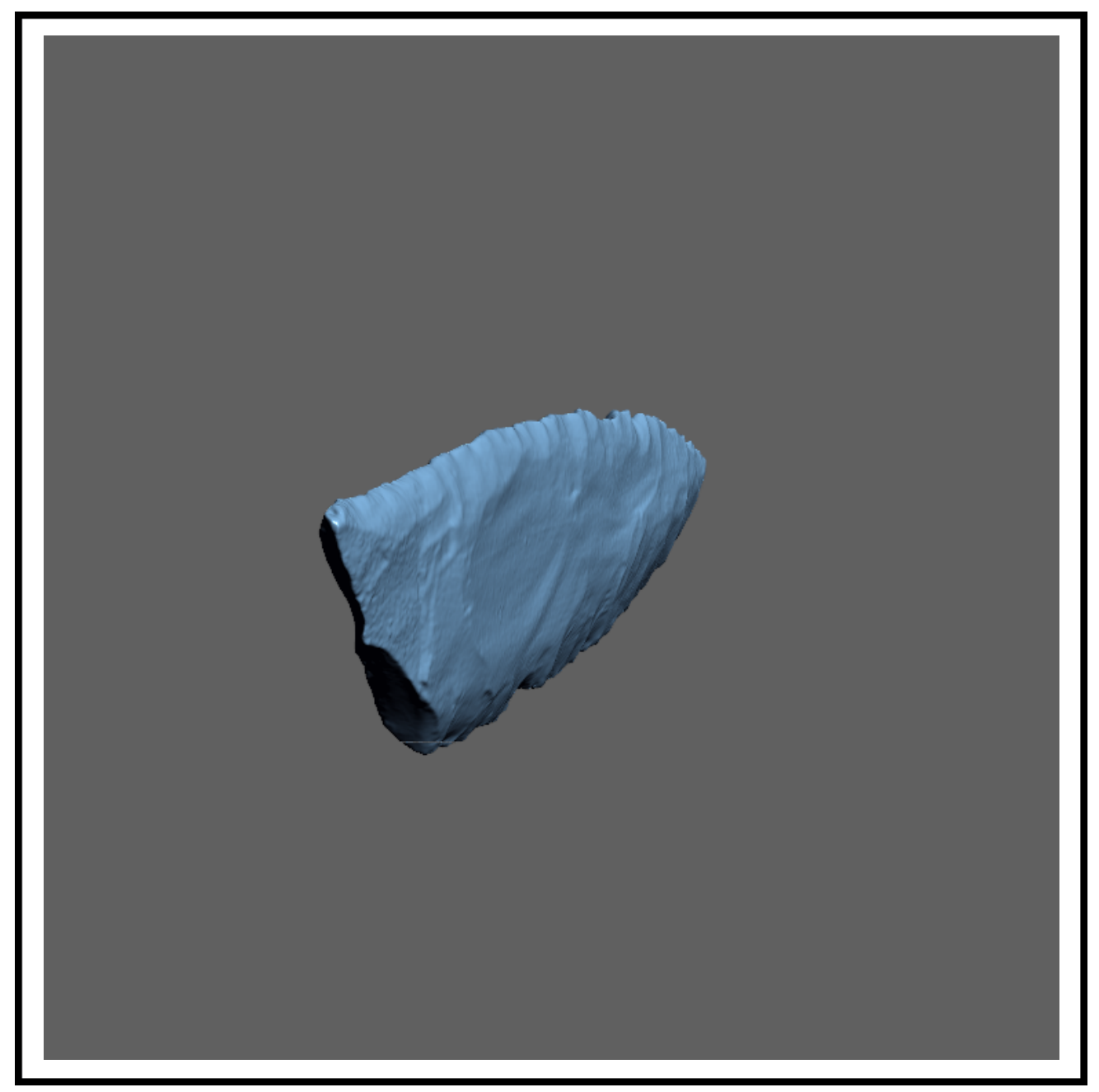

Figure 2: 3D scan of GAULT 41BL323 LOT1040-113. This is a 3D figure that can be rotated, measured and otherwise quantified. To activate the figure, this article must be downloaded to your computer. Activate the figure by clicking on the image, then click/drag to rotate.

\subsection{Context}

While the detailed context of these artifacts is discussed elsewhere Collins (2002, 2007); Bradley et al. (2010); Rodrigues et al. (2016); Speer (2014); Waters et al. (2011), an abbreviated listing is included in Table 1 , and in each of the Zenodo entries. Three Clovis points were recovered from Area 8 (2621-1, 36-42, and 191-174). Two further points, 2643-15 and 1323-1, were recovered from areas seven and four respectively. Finally, Clovis points 2624-1 and 1040-113 were recovered from the surface.

\subsection{Temporal Coverage}

To date, a total of six luminescence ages associated with the Clovis deposits have been reported; four from Area 15 Rodrigues et al. (2016), and two from Area 8 Waters et al. (2011). These ages fit within the known age range for the Clovis period, approximately 13,500 to 
Table 1: Context of Scanned Artifacts

\begin{tabular}{lll}
\hline Artifact No. & Description & Provenience \\
\hline $2621-1$ & Clovis Pt & Area 8 \\
$36-42$ & Clovis Pt & Area 8 \\
$2643-15$ & Clovis Pt & Area 7 \\
$191-174$ & Clovis Pt & Area 8 \\
$2624-1$ & Clovis Pt & Surface \\
$1323-1$ & Clovis Pt & Area 4 \\
$1040-113$ & Clovis Pt & Surface (Area 8) \\
\hline
\end{tabular}

12,800 cal BP Holliday (2000); Meltzer (2009) (Figure 3).

\section{Methods}

Selected artifacts were scanned using a NextEngineHD running ScanStudioHD Pro. Scan data were collected at the highest HD setting using eight divisions, then trimmed, aligned, fused and polished in ScanStudioHD Pro before being exported as ASCII.stl and ASCII.ply files prior to post-processing Galeazzi et al. (2014); Weyrich et al. (2004). Those data were then imported into Geomagic Design X, where the final meshes were aligned and processed.

\subsection{Steps}

To align each scan, a reference vector was inserted, followed by a reference point at the confluence of the vector and the mesh (using a projection) at the central base. A plane was inserted using the pick point and normal axis function, utilizing the vector as the normal axis, and the projected point as the pick point. Both elements (reference vector and reference point) of reference geometry were then utilized in an interactive alignment, with the the reference vector as the moving vector, and the reference point as the moving point (Figure 2). Alignment has proven to be an important factor in downstream analyses, particularly when making the transition from Design X and Control to SolidWorks or other CAD-based platform Selden Jr. (2015) like those used to generate the 3D puzzles (Figure 4).

Post-processing of each 3D mesh began with the healing wizard function in Design X, correcting problematic issues with non-manifold poly-vertices, folded poly-faces, dangling poly-faces, small clusters, small poly-faces, non-manifold poly-faces, crossing poly-faces, and small tunnels. The rewrap function was then used to render the final mesh. Upon completion of post-processing, each mesh was decimated by 50 percent prior to saving then export as an ASCII.ply. Decimation of the mesh decreases file size while increasing ease of use on standard computers.

\subsection{D Puzzles}

In addition to the 3D models, one 3D cardboard puzzle was created (for GAULT 41BL323 LOT1040-113 Selden Jr. (2016a)) to augment the on-site efforts of the interpretive staff by providing a physical model through which visitors can interact with the digital proxy. These cardboard puzzles were generated using Autodesk 123D Make Autodesk (2015), and the plans for the cardboard puzzles (Figure 5) accompanied the uploads to Zenodo. Those plans can 


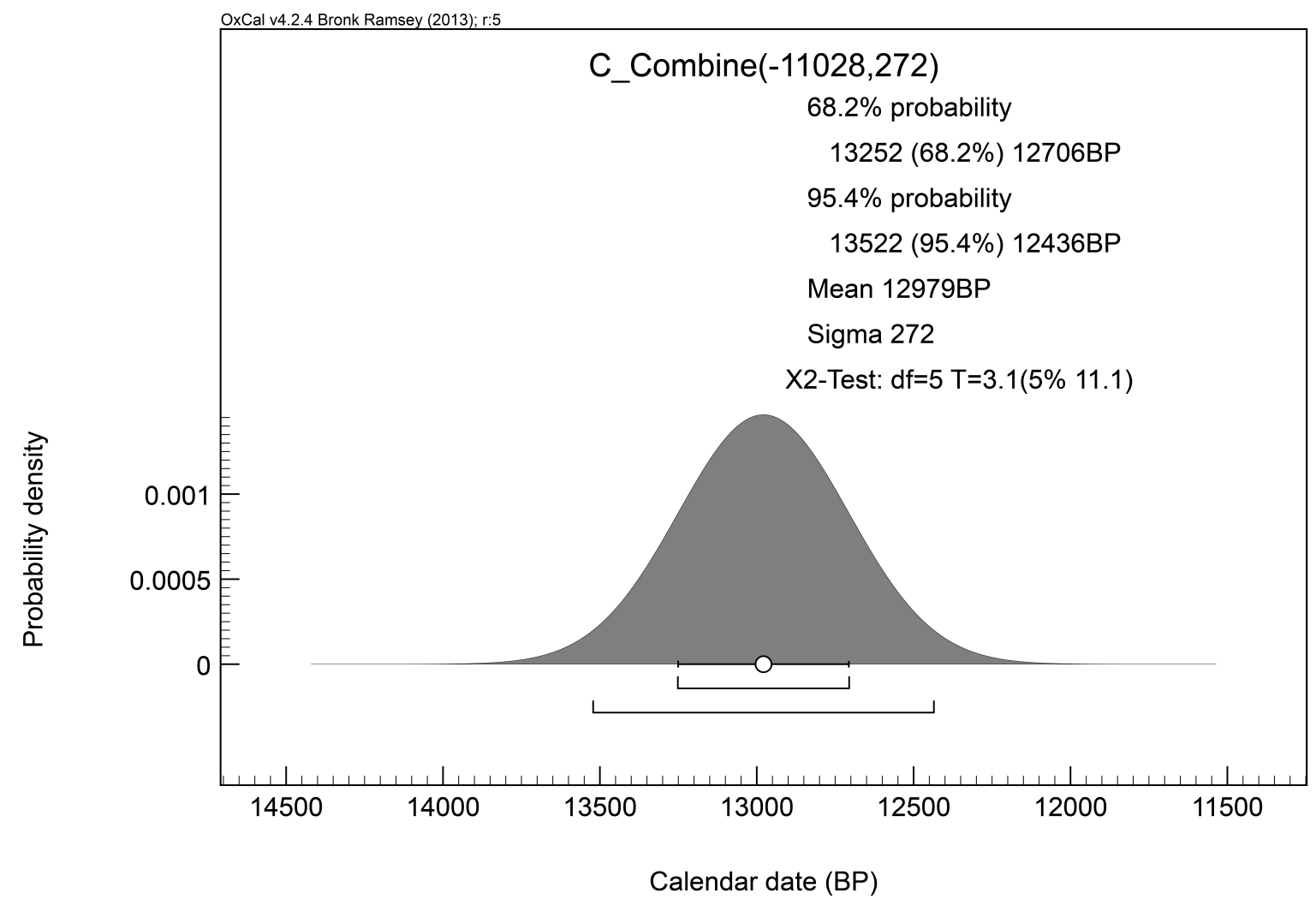

Figure 3: Luminescence age range associated with the Clovis-age deposits from the Gault Site. All dates $(n=6)$ were combined using the C_Combine function in OxCal v.4.2.4 (Bronk Ramsey 1995).

be downloaded, glued to cardboard, then cut out to create a tangible model of a Clovis point. These files were uploaded to Zenodo in .pdf format, and are also compatible with most laser cutters.

\section{Data Description}

\subsection{Collection Name}

3D Scans from the Gault Site

\subsection{Data Type}

Decimated meshes

\subsection{Format Names and Versions}

ASCII.ply (mesh) 


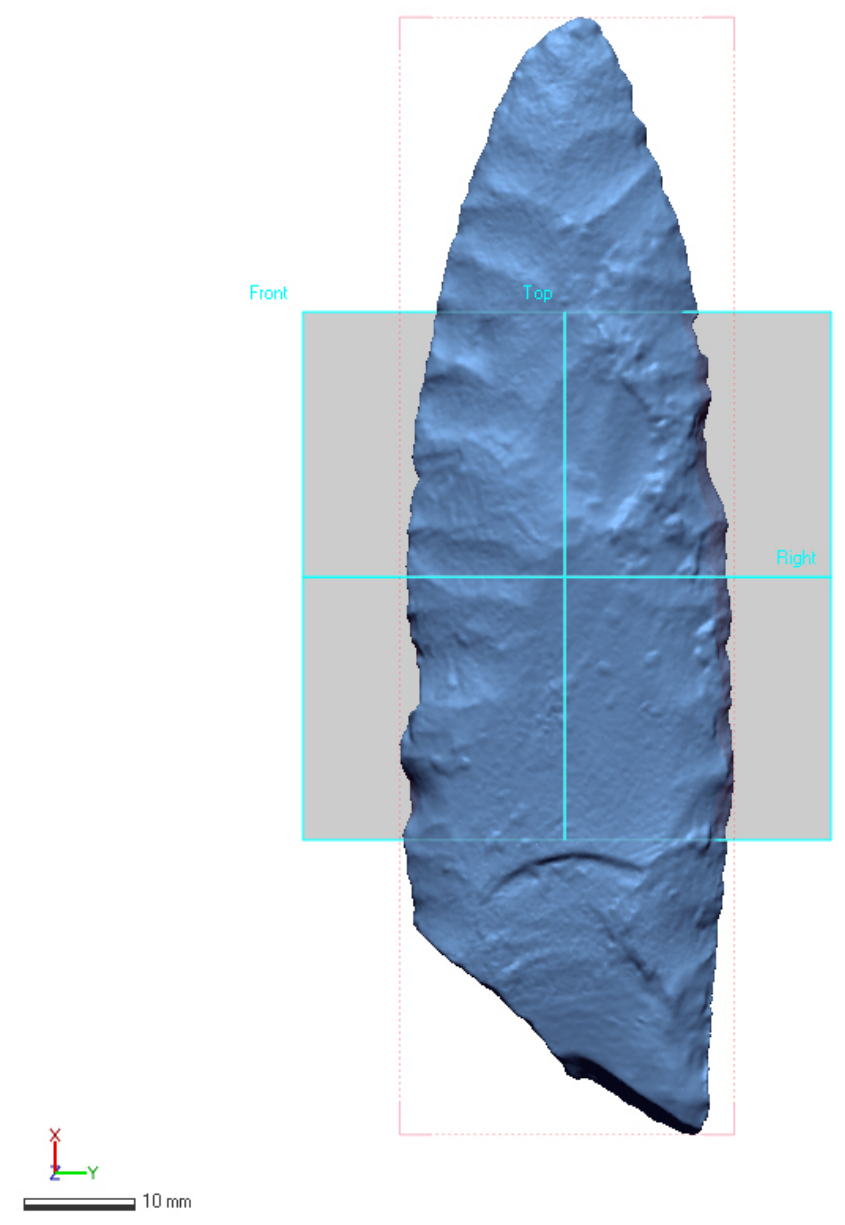

Figure 4: Aligned 3D mesh for GAULT 41BL323 LOT1040-113 showing reference planes.

\subsection{Creation Dates}

August 19, 2016

\subsection{Dataset Creators}

Robert Z. Selden Jr.

\subsection{Language}

English

\subsection{License}

Creative Commons Attribution 


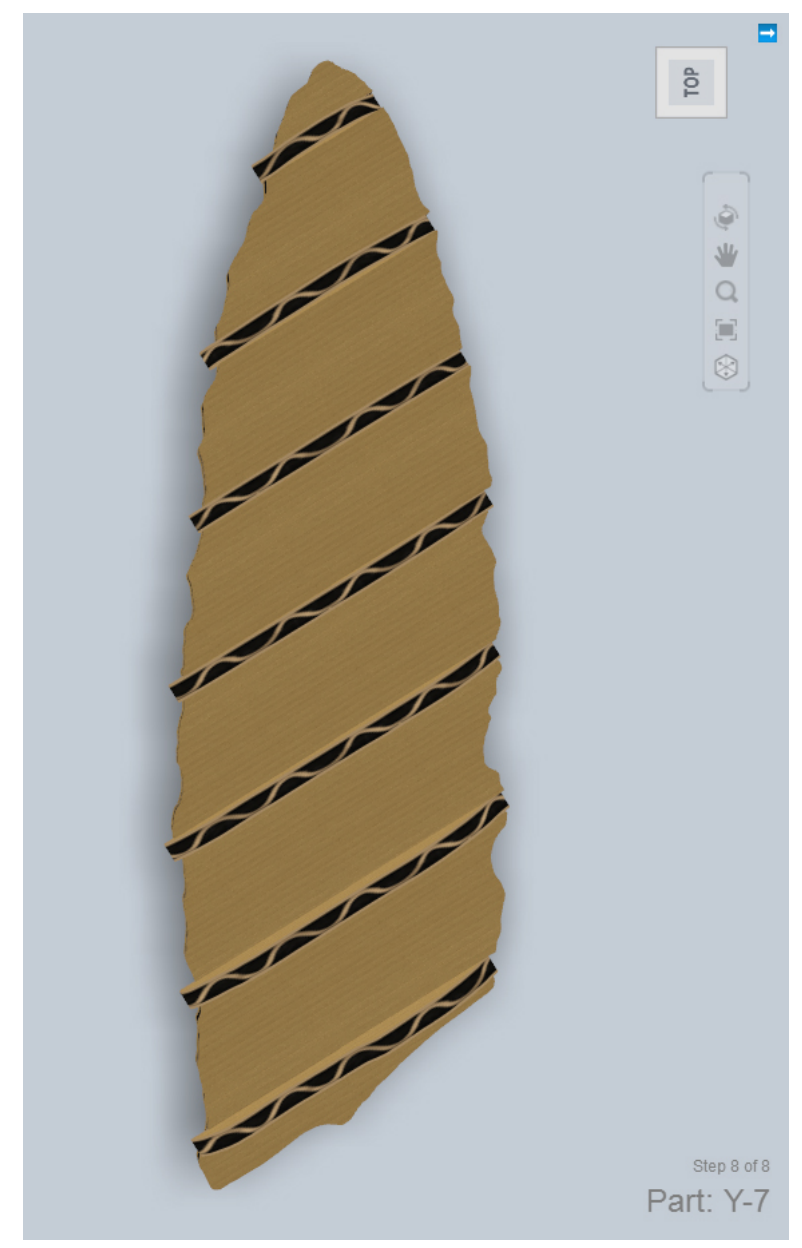

Figure 5: Modeled 3D puzzle of GAULT 41BL323 Lot1040-113 Selden Jr. (2016a) created with Autodesk 123D Make at a uniform scale.

\subsection{Repository Location}

3D Scans from the Gault Site

- GAULT 41BL323 LOT2621-1 (Selden Jr. 2016d) (https://doi.org/10.5281/zenodo.163947)

- GAULT 41BL323 LOT36-42 (Selden Jr. 2016g) (https://doi.org/10.5281/zenodo.163942)

- GAULT 41BL323 LOT2643-15 (Selden Jr. 2016f) (https://doi.org/10.5281/zenodo.163944)

- GAULT 41BL323 LOTAM191-174 (Selden Jr. 2016c) (https://doi.org/10.5281/zenodo.163945)

- GAULT 41BL323 LOT2624-1 (Selden Jr. 2016e) 
(https://doi.org/10.5281/zenodo.163946)

- GAULT 41BL323 LOTNH1323-1 (Selden Jr. 2016h)

(https://doi.org/10.5281/zenodo.163948)

- GAULT 41BL323 LOT1040-113 (Selden Jr. 2016b)

(https://doi.org/10.5281/zenodo.61413)

\subsection{Data Publication Date}

October 31, 2016

\section{Reuse Potential}

Those data from this project have long-term and wide-ranging reuse potential, of which many applications may (likely) not yet have been contemplated. While the primary purpose of this endeavor was to document these resources for use in additional analytical and outreach efforts, one of the projectile points has since been modeled as a 3D puzzle that can be cut out using materials that are easily acquired by most (i.e., a cardboard box).

These data have significant reuse potential in the sciences and digital humanities where they can augment both qualitative and quantitative studies. They also hold promise for clarifying questions of the shape, form, size and asymmetry of these artifacts, which can be addressed in analyses of asymmetry and geometric morphometrics.

\section{Acknowledgments}

We extend our gratitude to the Gault School of Archaeological Research and to Texas State University for providing the requisite permissions and access needed to scan this selection of artifacts. We also thank Dr. Loren G. Davis and Dr. Bruce Bradley for their comments on an earlier draft. Research at the Gault Site was funded in part by NSF Grant 0920549 to Texas State University, San Marcos, by The Gault School of Archaeological Research, and by private donors.

The 3D model used in Figure 2 was generated as a .ply in Design X and converted to a .u3d in DAZ Studio.

\section{References}

Ahmed, N., Carter, M., and Ferris, N. (2014). Sustainable Archaeology through Progressive Assembly 3D Digitization. World Archaeology, 46(1):137-154.

Autodesk (2015). 123D Make, http://www.123dapp.com/make.

Bradley, B. A., Collins, M. B., and Hemmings, C. A. (2010). Clovis Technology. International Monographs in Prehistory, Archaeological Series 17, Ann Arbor, Michigan. 
Bronk Ramsey, C. (1995). Radiocarbon Calibration and Analysis of Stratigraphy: The OxCal Program. Radiocarbon, 37(2):425-430.

Buchanan, B. and Collard, M. (2010). A Geometric Morphometrics-Based Assessment of Blade Shape Differences among paleoindian Projectile Point Types from Western North America. Journal of Archaeological Science, 37(2):350-359.

Buchanan, B., Collard, M., Hamilton, M. J., and O'Brien, M. J. (2011). Points and Prey: A Quantitative Test of the Hypothesis that Prey Size Influences Early Paleoindian Projectile Point Form. Journal of Archaeological Science, 38(4):852-864.

Buchanan, B., Johnson, E., Strauss, R. E., and Lewis, P. J. (2007). A Morphometric Approach to Assessing Late Paleoindian Projectile Point Variability on the Southern High Plains. Plains Anthropologist, 52(203):279-299.

Buchanan, B., Kilby, J. D., Huckell, B. B., O'Brien, M. J., and Collard, M. (2012). A Morphometric Assessment of the Intended Function of Cached Clovis Points. PLoS One, $7(2): \mathrm{e} 30530$.

Buchanan, B., O'Brien, M. J., and Collard, M. (2013). Continent-Wide or Region-Specific? a Geometric Morphometrics-Based Assessment of Variation in Clovis Point Shape. Archaeological and Anthropological Sciences, 6(2):145-162.

Buckley, M., Collins, M., and Thomas-Oates, J. (2008). A Method of Isolating the Collagen (I) Alpha2 Chain Carboxytelopeptide for Species Identification in Bone Fragments. Analytical Biochemistry, 374(2):325-334.

Carlson, E. S. (2014). Representation and Structure Conflict in the Digital Age: Reassessing Archaeological Illustration and the Use of Cubist Techniques in Depicting Images of the Past. Advances in Archaeological Practice, 2(4):269-284.

Collins, M. B. (2002). The Gault Site, Texas, and Clovis Research. Athena Review, 3(2):31-42.

Collins, M. B. (2007). Discerning Clovis Subsistence from Stone Artifacts and Site Distributions on the Southern Plains Periphery. In Walker, R. B. and Driskell, B. N., editors, Foragers of the Terminal Pleistocence in North America, pages 59-87. University of Nebraska Press, Lincoln.

Costin, C. L. (2001). Craft Production Systems. In Feinman, G. M. and Price, T. D., editors, Archaeology at the Millennium: A Sourcebook, pages 273-327. Kluwar Academic/Plenum Press, New York.

Costin, C. L. (2005). Craft Production. In Maschner, J. D. G., editor, Handbook of Archaeological Methods, pages 1034-1107. AltaMira, Walnut Creek.

Galeazzi, F., Moyes, H., and Aldenderfer, M. (2014). Defining Best 3D Practices in Archaeology: Comparing Laser Scanning and Dense Stereo Matching Techniques for 3D Intrasite Data Recording. Advances in Archaeological Practice, 2(4):353-365.

Holliday, V. T. (2000). The Evolution of Paleoindian Geochronology and Typology on the Great Plains. Geoarchaeology, 15(3):227. 
Hosfield, R. (2009). Modes of Transmission and Material Culture Patterns in Craft Skills. In Shennan, S., editor, Pattern and Process in Cultural Evolution, pages 45-60. University of California Press.

Keenan Early, E. (2016). Improving Species Identification in Texas: The Case for ZooMS in North America. Paper presented to the $87^{\text {th }}$ Texas Archeological Society, Nagadoches, TX, October 28, 2016.

Kuzminsky, S. C. and Gardiner, M. S. (2012). Three-Dimensional Laser Scanning: Potential Uses for Museum Conservation and Scientific Research. Journal of Archaeological Science, 39(8):2744-2751.

Lemke, A. K., Wernecke, D. C., and Collins, M. B. (2015). Early Art in North America: Clovis and Later Paleoindian Incised Artifacts from the Gault Site, Texas (41BL323). American Antiquity, 79(4):113-133.

Lycett, S. J. (2015). Cultural evolutionary approaches to artifact variation over time and space: Basis, progress, and prospects. Journal of Archaeological Science, 56:21-31.

Magnani, M. (2014). Three-Dimensional Alternatives to Lithic Illustration. Advances in Archaeological Practice, 2(4):285-297.

Means, B. K., McCuistion, A., and Bowles, C. (2013). Virtual Artifact Curation of the Historical Past and the NextEngine Desktop 3D Scanner. Technical Briefs in Historical Archaeology, 7:1-12.

Meltzer, D. J. (2009). First Peoples in a New World. University of California Press, Berkeley, CA.

Morgan, C. and Eve, S. (2012). DIY and Digital Archaeology: What are you Doing to Participate? World Archaeology, 44(4):521-537.

Rodrigues, K., Rink, W. J., Collins, M. B., Williams, T. J. J., Keen-Zebert, A., Lopez, G. I., Lopez, G. I., and Rodrigues, K. (2016). OSL ages of the Clovis, Late Paleoindian, and Archaic Components at Area 15 of the Gault Site, Central Texas, U.S.A. Journal of Archaeological Science: Reports, 7:94-103.

Selden Jr., R. Z. (2015). 3D Scan Data of Caddo Burial Vessels from the McSpadden Site near Frankston, Texas. CRHR Research Reports, 1:Article 5.

Selden Jr., R. Z. (2016a). Gault 41BL323 Lot1040-113 3D Puzzle, Zenodo, https://doi.org/10.5281/zenodo.163973.

Selden Jr., R. Z. (2016b). Gault 41BL323 Lot1040-113, Zenodo, https://doi.org/10.5281/zenodo.61413.

Selden Jr., R. Z. (2016c). Gault 41BL323 Lot191-174, Zenodo, https://doi.org/10.5281/zenodo.163945.

Selden Jr., R. Z. (2016d). Gault 41BL323 Lot2621-1, Zenodo, https://doi.org/10.5281/zenodo.163947. 


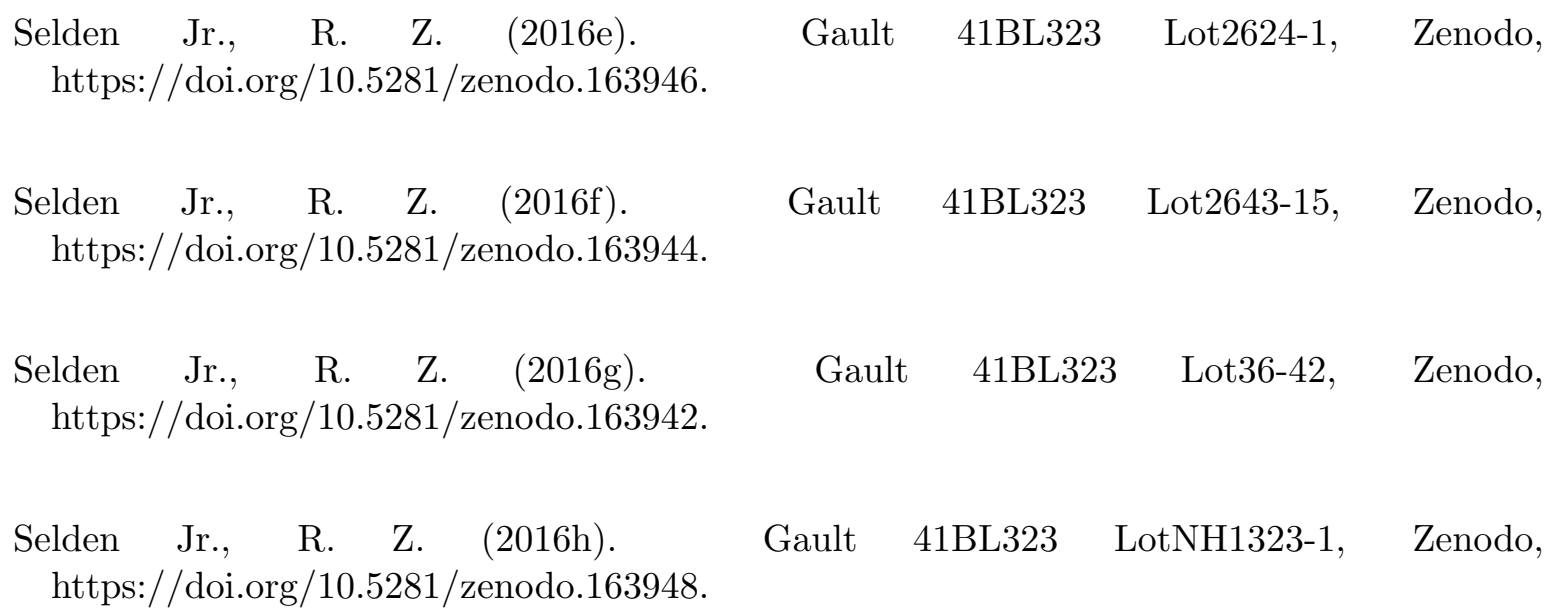

Shott, M. J. (2011). History Written in Stone: Evolutionary Analysis of Stone Tools in Archeology. Evolution: Education and Outreach, 4(3):435-445.

Shott, M. J. (2014). Digitizing Archaeology: A Subtle Revolution in Analysis. World Archaeology, 46(1):1-9.

Shott, M. J. (2015). Theory in Archaeology: Morphometric Approaches to the Study of Fluted Points. In Goodale, N. and Andrefsky Jr, W., editors, Lithic Technological Systems and Evolutionary Theory, pages 48-60. Cambridge University Press, Cambridge.

Shott, M. J. and Trail, B. W. (2012). New Developments in Lithic Analysis: Laser Scanning and Digital Modeling. The SAA Archaeological Record, pages 12-17.

Speer, C. A. (2014). LA-ICP-MS Analysis of Clovis Period Projectile Points from the Gault Site. Journal of Archaeological Science, 52:1-11.

Velchoff Littlefield, N. (2015). Exploring the Interpretive Potential of Clovis Waste Flakes. M.Ph Dissertation, Department of Archaeology, University of Exeter, UK.

Waters, M. R., Pevny, C. D., and Carlson, D. L. (2011). Clovis Lithic Technology: Investigation of a Stratified Workshop at the Gault Site, Texas. Texas A\&M University Press, College Station, Texas.

Weyrich, T., Pauly, M., Keiser, R., Heinzle, S., Scandella, S., and Gross, M. (2004). PostProcessing of Scanned 3D Surface Data. Eurographics Symposium on Point-Based Graphics.

Williams, T. J. (2016). The morphology and technology of clovis flat-backed cores from the gault site (41bl323), texas. Lithic Technology, 7261(April):1-15. 


\author{
Affiliation: \\ Robert Z. Selden Jr. \\ Center for Regional Heritage Research, Stephen F. Austin State University \\ Nacogdoches, Texas, USA \\ E-mail: seldenjrz@sfasu.edu \\ URL: https://selden3d.com/
}

SocArXiv on Twitter

Temporary Home of SocArXiv Preprints

Preprint

osf.io/view/socarxiv/ https://twitter.com/socarxiv

https://osf.io/view/socarxiv/

Submitted: November 18, 2016

Accepted: November 18, 2016 